\title{
Replication-coupled chromatin assembly is required for the repression of basal transcription in vivo
}

\author{
Geneviève Almouzni ${ }^{1}$ and Alan P. Wolffe ${ }^{2}$ \\ Laboratory of Molecular Embryology, National Institute of Child Health and Human Development, \\ Bethesda, Maryland 20892 USA
}

\begin{abstract}
The chromatin assembly process coupled to DNA synthesis in the Xenopus oocyte nucleus is significantly more repressive toward basal transcription than chromatin assembly on duplex DNA. We show that chromatin assembly concurrent with DNA synthesis over the promoter region itself is causal for repression. However, the trans-activator Gal4-VP16 both relieves repression and activates transcription regardless of the chromatin assembly pathway. This activation is independent of whether Gal4-VP16 addition occurs before or after chromatin assembly. We propose that replication-coupled chromatin assembly represents a general mechanism to direct the efficient repression of basal transcription. However transcription induction by a specific activator, Gal4-VP16, occurs independent of this chromatin-mediated repression.
\end{abstract}

[Key Words: Chromatin assembly; DNA synthesis; basal transcription; transcriptional activator; chromatin-mediated repression; replication]

Received April 19, 1993; revised version accepted August 9, 1993.

In vivo, the duplication of a functional chromosome requires both the replication of DNA and the subsequent reassembly of nucleoprotein structures. Nucleosomes are transiently displaced by the advancing replication fork (Sogo et al. 1986; Bonne-Andrea et al. 1986; Krude and Knippers 1991; Randall and Kelly 1992); likewise, replication potentially disrupts a preexisting transcription complex (Miller and Nasmyth 1984; Wolffe and Brown 1986). In vitro experiments have shown that transcription factors and histone proteins can compete for binding to DNA regulatory elements following replication (Almouzni et al. 1990a, 1991). However the molecular mechanisms necessary to establish specific states of gene expression on newly replicated DNA have not been resolved (Weintraub 1985). Replication might provide a window of opportunity wherein the disruption of preexisting chromatin structures would allow modulation of gene activity (Brown 1984; Svaren and Chalkley 1990; Wolffe 1991).

Chromatin assembly is effectively coupled to replication (Worcel et al. 1978; Stillman 1986; Almouzni and Méchali 1988). Although chromatin assembly can also occur on nonreplicating templates, the molecular events involved differ (Almouzni et al. 1990b; Gruss et al. 1990). Many studies have demonstrated that repression of transcription occurs following prior chromatin assembly on

\footnotetext{
${ }^{1}$ Present address: Institut Jacques Monod, Centre National de la Recherche Scientifique-Tour 43, 75251 Paris Cedex 05, France.

${ }^{2}$ Corresponding author.
}

nonreplicating templates in vitro (for review, see Felsenfeld 1992). However, marked differences in chromatin structure and the capacity to induce transcriptional activity occur dependent on whether promoters are present on replicating episomes or nonreplicating transiently transfected DNA (see, e.g., Archer et al. 1992). Thus, it is possible that the coupling of chromatin assembly to replication in vivo has important consequences for gene regulation. However, this possibility has not been directly investigated until now. Our previous in vitro studies using simple class III genes have demonstrated that the coupling of chromatin assembly to replication represses transcription more effectively than chromatin assembly on duplex templates (Almouzni et al. 1990a, 1991; Clark and Wolffe 1991). We have now explored the impact of replication-coupled chromatin assembly on the expression of class II genes in vivo using microinjection of $\mathrm{Xe}$ nopus oocyte nuclei.

Microinjection of Xenopus oocyte nuclei provides a convenient and highly efficient means of transcribing cloned genes in vivo. This approach has been used for the initial definition of gene regulatory elements (Brown and Gurdon 1977; McKnight and Kingsbury 1982): the assembly of chromatin on exogenous DNA (Wyllie et al. 1978; Ryoji and Worcel 1984); the examination of chromatin-mediated gene repression (Weisbrod et al. 1982); and the determination of the influence of DNA topology on transcription (Harland et al. 1983). In every instance, results in oocyte nuclei have been substantiated by later experiments in somatic cells/Gurdon and Wickens 
1983; Gurdon and Wakefield 1986). Chromatin assembled in oocytes or oocyte extracts contains all four core histones, including histone $\mathrm{H} 4$, which is initially diacetylated, and a linker histone B4 (Smith et al. 1988; Shimamura and Worcel 1989; Dimitrov et al. 1993; S. Dimitrov, G. Almouzni, M. Dasso and A. Wolffe, in prep.). Using this system, we establish that replicationcoupled chromatin assembly is necessary to effectively repress basal transcription from class II gene promoters in vivo. However in spite of the differences in basal transcription between replicating and nonreplicating templates, the association of a specific activator with upstream elements both alleviates chromatin-mediated repression and activates transcription.

\section{Results}

\section{Differential transcription of replicating vs. nonreplicating templates in vivo}

The promoters used to examine transcription in the $X e$ nopus oocyte nucleus are those of the human cytomegalovirus (CMV) immediate early gene 1 (Boshart et al. 1985 ) and the Xenopus histone $\mathrm{H}^{\circ}$ gene (Khochbin and Wolffe 1993). In preliminary experiments, we found that both promoters direct the accurate initiation of transcription by RNA polymerase II in the Xenopus oocyte nucleus. First, we compared the accumulation of transcripts during an overnight incubation of oocytes microinjected with single- or double-stranded templates containing the $\mathrm{H}^{\circ}$ promoter (Fig. 1). The experiment revealed that far fewer transcripts accumulated when single-stranded DNA (ssDNA) was injected (Fig. 1A, lane 3) as compared with double-stranded DNA (dsDNA) (lane 2), although transcription initiation remains specific (not visible on this gel exposure; see also Fig. 3, below). The difference in the amount of transcription was not attributable simply to different amounts of DNA present in the nucleus, as the recovery of DNA from a fraction of the sample clearly showed (Fig. 1B,C) that the amount of dsDNA present after injection of ssDNA was even higher than the amount present after injection of the duplex template (Fig. 1C, cf. lanes 2 and $3)$. In other experiments we have established that transcription increases as a function of the amount of double-stranded template injected in this concentration range (not shown). Linear templates that are transcriptionally impaired make up $<15 \%$ of total DNA in both replicated and unreplicated samples (Harland et al. 1983; data not shown).

The low level of transcription seen when ssDNA is injected might simply be attributable to a delay in which the ssDNA is converted to the double-stranded form, as only dsDNA can act as a transcription template (see also Cortese et al. 1980; Almouzni et al. 1990a). Alternatively, it could be attributable to differences in transcription complex assembly or chromatin assembly dependent on replication. To address this issue, we initially determined the rate of conversion of single-stranded to dsDNA in the oocyte nucleus, and the efficiency of su-

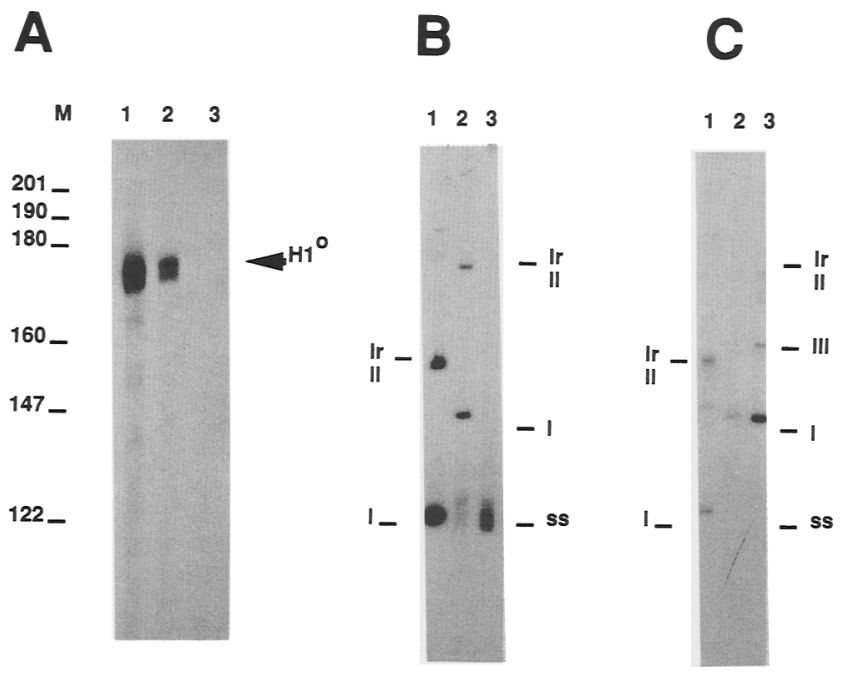

Figure 1. Comparison of transcript accumulation after injection of double-stranded or single-stranded templates into the germinal vesicles of oocytes. Groups of 15 oocytes were injected with the different templates $(100 \mu \mathrm{g} / \mathrm{ml})$ harboring the $\mathrm{H} 1^{\circ}$ promoter as follows: (Lane 1) Double-stranded pUC derivative; (lane 2) double-stranded M13 derivative; (lane 3) single-stranded $\mathrm{M} 13$ derivatives. After $18 \mathrm{hr}$ of incubation at $18^{\circ} \mathrm{C}$, the oocytes were collected and processed in parallel for both RNA analysis $(A)$ and DNA analysis $(C)$. RNA analysis was performed by primer extension (Materials and methods). The position of the correct primer extension product is indicated by an arrow labeled $\mathrm{H} 1^{\circ}$. Markers were obtained from a $\mathrm{Hpall}$ digestion of plasmid pBR322. DNA was purified, analyzed on an agarose gel, and blotted (Materials and methods). On the same gel, aliquots of the solutions of DNA used for microinjection were run in parallel $(B)$. Different forms of DNA are indicated at left for the pUC derivatives and at right for the M13 derivatives. Doublestranded form I (closed circular supercoiled), form II (nicked circles), form Ir (closed circular relaxed), form III (linear molecules), and ssDNA (ss) are indicated.

percoiling of the duplex templates dependent on nucleosome assembly.

\section{Chromatin assembly on replicating single-stranded and nonreplicating duplex templates in vivo}

The fate of a mixture of equal masses of single-stranded (M13) or dsDNA (pUC9) microinjected at the same time into the oocyte nucleus is followed by extraction at different times after microinjection and resolution of topoisomers by agarose gel electrophoresis, Southern blotting, and hybridization with radioactively labeled pUC9 or M13 DNA (Fig. 2A). Within 15 min, supercoiled dsDNA is relaxed (Fig. 2A, left) and is then gradually supercoiled again, with the level of supercoiling increasing up to the final incubation time of $3 \mathrm{hr}$, (see also Ryoji and Worcel 1984). ssDNA is converted by complementary strand synthesis into dsDNA detected by $45 \mathrm{~min}$ (Fig. 2A, right). These dsDNA molecules are fully supercoiled in that same time frame and contain as many nucleosomes as templates incubated for 3-hr (data not shown). In com- 




Figure 2. Fate of DNA injected into germinal vesicles of oocytes when either the double- or single-stranded form is used. (A) Groups of 5-10 oocytes were injected as described in Materials and methods with $30 \mathrm{nl}$ of DNA solution at 100 $\mu \mathrm{g} / \mathrm{ml}$ total containing equivalent amounts of dsDNA pUC9 and ssDNA M13. After incubation for various times (as indicated), oocytes were processed for DNA purification. DNA was analyzed by electrophoresis on a $1 \%$ agarose gel in TAE buffer run at low voltage for $24 \mathrm{hr}$. After gel blotting the same filter was probed twice, once with a ${ }^{32}$ P-labeled random primed pUC9 probe (left), and the second time with an M13 probe (right). The various DNA forms are indicated: doublestranded form I (closed circular supercoiled), form II (nicked circles), form Ir (closed circular relaxed), form III (linear molecules) and ssDNA (ss). Note that for the ss form, circular and linear forms can be distinguished on this type of gel / the circular form is the upper band, the linear form the lower band). This latter form arises from ssDNA in the cytoplasm that is then nicked and finally degraded. (B) Analysis by micrococcal nuclease digestion of DNA injected into germinal vesicles of oocytes in double-stranded or singlestranded form. Groups of 15 oocytes were injected with DNA solutions as follows: $(\text { Left })^{32} \mathrm{P}$ labeled double-stranded derivatives obtained by conversion of ssDNA into dsDNA in an egg extract in the presence of $\left[\alpha^{-32} \mathrm{P}\right] \mathrm{dATP}$; (right) single-stranded M13 derivatives together with $\left[\alpha^{-32} \mathrm{P}\right] \mathrm{dATP}$ were injected (the ratio of $\left[\alpha^{-32} \mathrm{P}\right]-$ dATP to DNA is the same as in the labeling in vitro of dsDNA). After 4 or $16 \mathrm{hr}$ (as indicated), the oocytes were homogenized in buffer $20 \mathrm{~mm}$ HEPES at $\mathrm{pH} 7.5,70 \mathrm{~mm} \mathrm{KCl}, 1 \mathrm{~mm}$ DTT, $5 \%$ sucrose) and adjusted to $3 \mathrm{mM} \mathrm{CaCl}{ }_{2}$ before addition of micrococcal nuclease (60 units). Aliquots were taken at various times as indicated, made up to $30 \mathrm{mM}$ EDTA, $0.5 \%$ SDS, and processed for DNA analysis on a $1.5 \%$ agarose gel in TAE buffer. An autoradiograph is shown. Positions of mononucleosome (mono), dinucleosome (di), and trinucleosome (tri) digestion products are indicated. Size calibration is achieved using a 123-bp ladder from BRL. parison with the chromatin assembly process on the DNA microinjected in duplex form, the replication-coupled chromatin assembly appears much more efficient in that very few partially assembled templates appear in the reaction (see also Stillman 1986; Almouzni and Méchali 1988a; Almouzni et al. 1990b). Thus, there is only a brief lag (45 min) between the injection of ssDNA and its complete conversion to duplex form. Quantitation of the amount of ssDNA converted into double-stranded form indicates that some loss of material occurs, probably owing to some leakage of DNA into the cytoplasm where it is degraded (Wyllie et al. 1978). This probably accounts for the presence of both linear and circular singlestranded M13 DNA in the microinjected samples; the linear ssDNA is cytoplasmic and disappears after $3 \mathrm{hr}$ as it is degraded (Wyllie et al. 1977). Nevertheless, the conversion of closer circular single-stranded M13 DNA to duplex form is $>50 \%$ efficient within a 3 -hr time period (Fig. 2A; see also Fig. 1).

As the appearance of supercoiling correlates with nucleosome formation, we confirmed that the supercoiling of the dsDNA and of the replicated single-stranded template was the result of nucleosome assembly after two different incubation periods. Radiolabeled doublestranded M13 DNA or single-stranded M13 DNA was microinjected into oocyte nuclei, together with $\left[\alpha^{-32} \mathrm{P}\right] \mathrm{d}$ ATP to follow the synthesis of dsDNA. Similar kinetics of supercoiling in these independent injection experiments are observed as in Figure 2A /data not shown). These nucleoprotein complexes are then digested with micrococcal nuclease either after 4 or $16 \mathrm{hr}$ of assembly, and the labeled DNA fragments are extracted and resolved on a $1.5 \%$ agarose gel (Fig. 2B) for both templates. Nucleosomes are assembled with a 
physiological spacing of $\sim 180-190$ bp (Young and Carroll 1983). No major changes in chromatin organization occur between 4 and $16 \mathrm{hr}$, although large differences in transcriptional activity occur between initially single- or double-stranded templates over this time interval (see Fig. 3).

We conclude that microinjection of ssDNA or dsDNA into the nucleus provides two pathways for chromatin assembly. The first occurs on dsDNA and does not involve DNA synthesis. We confirmed that dsDNA templates did not replicate in Xenopus oocyte nuclei (Graham et al. 1966; Gurdon 1968; Harland and Laskey 1980; data not shown). The second pathway requires DNA synthesis [nucleosomes do not form on ssDNA (Almouzni et al. 1990b)] and occurs during complementary strand synthesis on ssDNA. Importantly, replicating singlestranded templates appear as fully supercoiled molecules as early as $45 \mathrm{~min}$ after injection, whereas injected dsDNA is supercoiled in a much slower reaction, with maximal levels of supercoiling occurring only after $3 \mathrm{hr}$ and further supercoiling continuing beyond this time (data not shown). This suggests that chromatin assembly is coupled to replication in vivo, as described previously in vitro (Almouzni and Méchali 1988; Almouzni et al. 1990b). As $45 \mathrm{~min}$ is required for ssDNA to be converted to duplex form and because only dsDNA is competent for transcription, we tested the possibility that this 45 min delay is sufficient to explain the difference in transcriptional properties between the two types of template. In this case, we might expect a kinetic analysis of transcription to reveal a longer lag period for ssDNA rather than dsDNA, but after this time comparable transcriptional efficiencies would be achieved.

\section{Transcription from a replicating template is delayed but is also only transient and inefficient}

When injected as double-stranded templates, both the $\mathrm{CMV}$ and histone $\mathrm{Hl}^{\circ}$ promoters direct specific transcription leading to the continual accumulation of mRNA for $>4 \mathrm{hr}$ (Fig. 3A, left). However, there is an initial lag period of $15 \mathrm{~min}$ before transcripts appear (Fig. 3A). This is consistent with the time-dependent assembly of a functional RNA polymerase II preinitiation com-
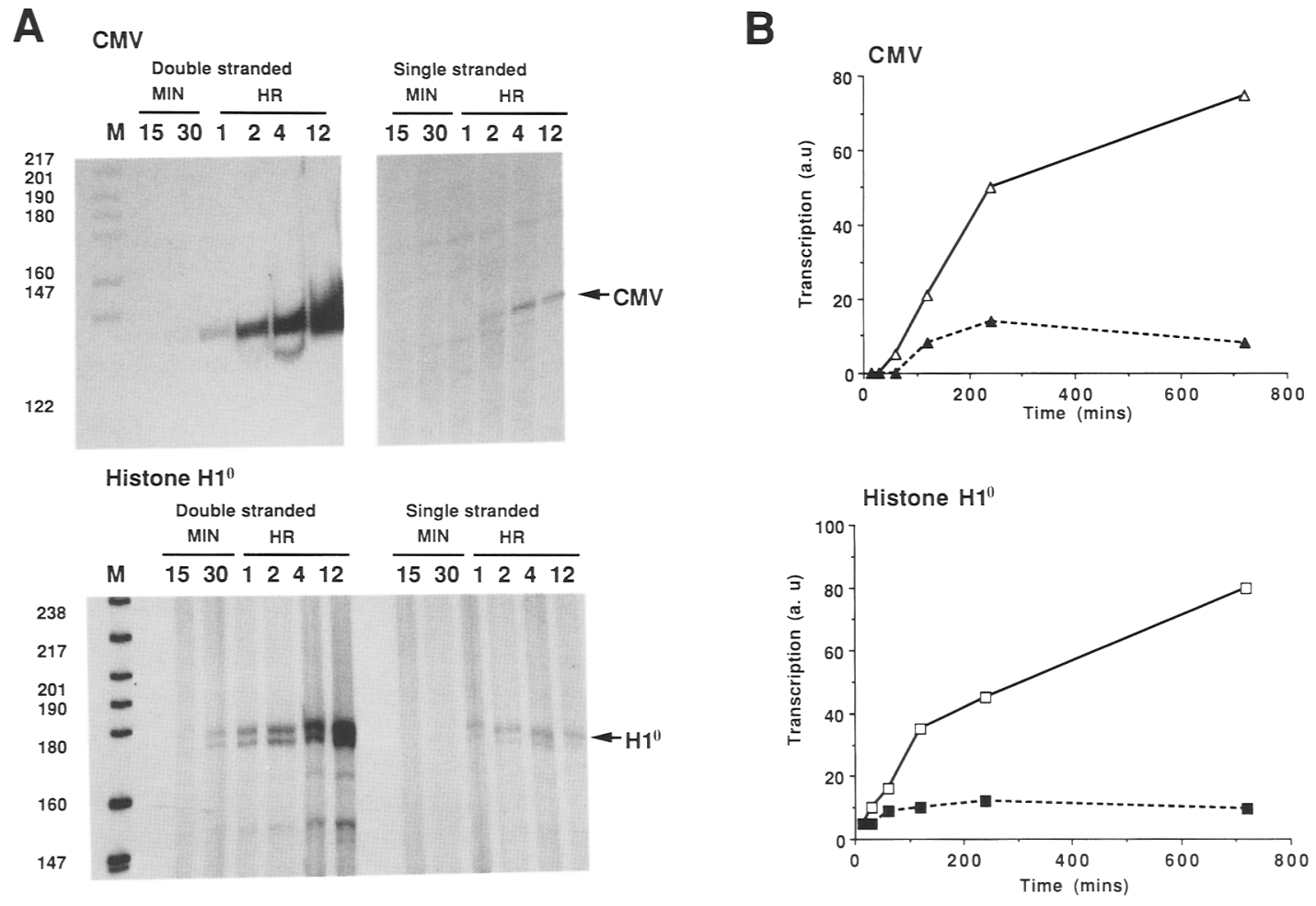

Figure 3. Time course for transcription from two different polymerase II promoters after injection into the germinal vesicles of oocytes in double- or single-stranded form. Groups of 15 oocytes were injected with DNA solutions as in Fig. 1. After the incubation times indicated, oocytes were collected and processed both for RNA analysis $(A)$ and for DNA analysis to enable quantification as a function of DNA recovery $(B)$. $(A)$ Transcription using the promoter of the major immediate early gene from human CMV (top) or the promoter of Xenopus histone $\mathrm{Hl}^{\circ}$ (bottom), as indicated, was analyzed by primer extension. (Left) The microinjection of the doublestranded derivative; (right) the use of the single-stranded derivatives. The positions of the correct primer extension products reflecting accurate transcription initiation are indicated with arrows. Markers are obtained from a HpaII digestion of plasmid pBR322. (B) Quantitation of transcript accumulation relative to recovered dsDNA in arbitrary units (a.u) as a function of time for the CMV promoter $(\triangle)$ and the $\mathrm{H}^{\circ}$ promoter $(\square)$. Open symbols indicate microinjection of the double-stranded template; solid symbols indicate microinjection of the single-stranded template. Data are obtained by densitometric scanning of the gels shown in $A$, using DNA blots to normalize transcription signals to the amount of dsDNA recovered. 
plex in Xenopus extracts (Toyoda and Wolffe 1992). In contrast, when the same template is microinjected in single-stranded form, we observe a longer lag period $\{\sim 1$ $\mathrm{hr}$ ) before transcripts are detectable, and far fewer transcripts accumulate even by 4 or $12 \mathrm{hr}$ of incubation (Fig. $3 \mathrm{~A}$, right). Quantitation of the data with respect to DNA recovered as double-stranded form confirmed this analysis (Fig. 3B). Thus, the initial lag period of $45 \mathrm{~min}$, before the first appearance of dsDNA following the injection of single-stranded templates, might account for the delay in the first appearance of transcripts. Importantly however, the transcriptional activity of the initially single-stranded template appears considerably reduced compared with the template injected in duplex form. Furthermore, the duration of active transcription from the replicated template is considerably shorter than for the duplex template. This suggests that events occurring after replication and the initial assembly of chromatin influence the final transcriptional state.

To assess whether there is any role for RNA degradation in determining the net accumulation of transcripts, we allowed $4 \mathrm{hr}$ to elapse following the injection of single- or double-stranded templates, before injection of $\alpha$-amanitin at a concentration sufficient to inhibit further RNA polymerase II transcription (Gurdon and Wakefield 1986). The transcripts accumulated in the first $4 \mathrm{hr}$ are stable for $>8 \mathrm{hr}$ (data not shown). Therefore, RNA instability does not appear to play a major role in determining the level of differential transcription between initially single-stranded and duplex templates.

We conclude that the reduced transcription of the initially single-stranded templates relative to the duplex templates is attributable, in part, to a longer lag period before transcription begins but, more significantly, to much less efficient transcription once dsDNA has been synthesized. We then wished to examine whether replication per se or the different pathways of replicationdependent or -independent chromatin assembly occurring in the oocyte nucleus might influence this differential transcription efficiency.

\section{Replication-dependent chromatin assembly selectively represses transcription in vivo}

To further examine the inhibitory influence on transcription observed on the replicated templates, we titrated the capacity of the oocyte nucleus to assemble chromatin using competitor DNA. We used bacteriophage $\lambda$ DNA as competitor DNA, as we found that it was less inhibitory to transcription through titration of trans-acting factors than $\mathrm{pBR}$ or $\mathrm{pUC}$ derivatives $\mathrm{Al}$ mouzni et al. 1990a). The injection of bacteriophage $\lambda$ DNA into the oocyte nucleus titrates nucleosome assembly, as reflected in the decrease in supercoiled form I DNA generated by replicating ssDNA in the nucleus (Fig. 4B). Densitometric analysis of the gel reveals $\sim 50 \%$ reduction in the proportion of fully supercoiled DNA (form I) compared with other topological forms. Each nucleosome introduces a single negative superhelical turn into closed circular DNA, so that when the histones are

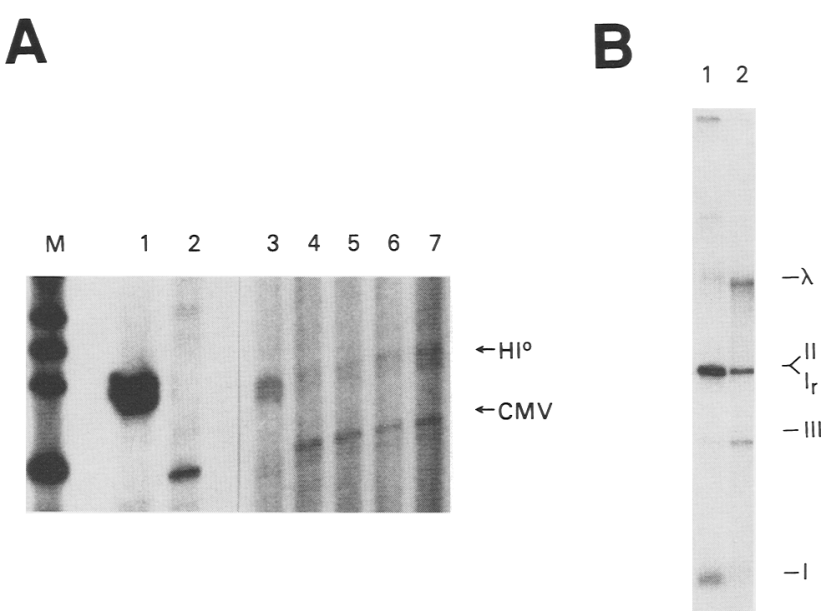

Figure 4. Titration of chromatin precursors with bacteriophage $\lambda$ DNA and the effect on transcription of replicating single-stranded CMV DNA and nonreplicating double-stranded $\mathrm{Hl}^{\circ}$ DNA. (A) Transcription reaction. Groups of 10 oocytes were injected with DNA and incubated for $16 \mathrm{hr}$ before processing for RNA analysis by primer extension. Lane 1 is a control for the extension products obtained from transcription of the histone $\mathrm{Hl}^{\circ}$ promoter. Lane 2 is a control for the extension products obtained from transcription of the CMV promoter. In lanes 3-7, a mixture of the $\mathrm{Hl}^{\circ}$ promoter in double-stranded form (100 $\mu \mathrm{g} / \mathrm{ml}$ ) and the CMV promoter in initially single-stranded form $(100 \mu \mathrm{g} / \mathrm{ml})$ has been injected in the presence of an increasing amount of $\lambda$ DNA: $0,200 \mu \mathrm{g} / \mathrm{ml}, 600 \mu \mathrm{g} / \mathrm{ml}, 1.2 \mathrm{mg} / \mathrm{ml}$, and 2.4 $\mathrm{mg} / \mathrm{ml}$, respectively. The positions of the extension products for accurate transcription initiation at the $\mathrm{H}^{\circ}$ and $\mathrm{CMV}$ promoter are indicated by arrows. The marker is a pBR322 digest with HpaII. (B) Titration of endogenous chromatin assembly. ssDNA $(200 \mu \mathrm{g} / \mathrm{ml})$ was injected together with $\left[\alpha^{-32} \mathrm{P}\right] \mathrm{dATP}$ and $\lambda$ DNA [0 (lane 1) or $200 \mu \mathrm{g} / \mathrm{ml}$ (lane 2)]. After $16 \mathrm{hr}$ of incubation, DNA was purified and analyzed by electrophoresis on a $1 \%$ agarose gel in TAE buffer. The corresponding autoradiograph is presented with the position of form I (closed circular supercoiled), form II (nicked circles), form Ir (closed circular relaxed), and form III (linear molecules), $\lambda$ DNA indicated. Incorporation of radiolabel into $\lambda$ DNA is most likely the result of repair mechanisms. The gel was scanned to quantitate the decrease in supercoiling following addition of $\lambda$ DNA.

titrated out, more relaxed circular DNA (form Ir) accumulates instead of supercoiled DNA (form I). Furthermore, the accumulation of approximately equivalent amounts of radiolabeled dsDNA generated from the single-stranded template (Fig. 4B, cf. lanes 1 and 2) indicates that complementary strand synthesis is not significantly inhibited by the presence of bacteriophage $\lambda$ DNA.

We then use mixtures of the CMV and histone $\mathrm{HI}^{\circ}$ promoters to examine whether any changes in transcription occur dependent on whether the templates are initially single or double stranded as histones are titrated onto the competitor DNA. A double-stranded template containing the histone $\mathrm{H}^{\circ}$ promoter, as an internal control, is mixed with a single-stranded template containing the CMV promoter. As expected (Fig. 4A, lane 3), the mixture of templates leads to more transcription from 
the duplex histone $\mathrm{H}^{\circ}$ promoter than from the initially single-stranded CMV promoter. We then titrate chromatin assembly using bacteriophage $\lambda$ DNA before the injection of the two templates. Transcription from the CMV promoter is greatly stimulated, whereas that from the histone $\mathrm{Hl}^{\circ}$ promoter is somewhat reduced (Fig. 4A, lanes 4-7). Our interpretation of this result is that titration of chromatin assembly activates transcription from the template that is initially single stranded and on which repressive chromatin assembly is coupled to complementary strand synthesis. In contrast, the process of chromatin assembly on dsDNA is much less inhibitory; hence, only a reduction of transcription from the duplex histone $\mathrm{H} 1^{\circ}$ promoter is seen following the addition of bacteriophage $\lambda$ DNA. This is probably attributable to the nonspecific titration of transcription factors by competitor DNA (Almouzni et al. 1990a).

We suggest that the low level of transcription derived from the initially single-stranded template is not attributable solely to any influence of (or requirement for) replication per se, but is attributable largely to the assembly of repressive chromatin structures dependent on the replication process.

Chromatin assembly on replicating DNA in vivo restricts nuclease access to DNA more effectively than chromatin assembly on duplex DNA

Repressive histone-DNA contacts over the promoter have been shown to prevent restriction endonuclease cleavage, whereas transcription factor interactions at a promoter region do not generally prevent restriction enzyme action (see Morse 1989; Workman et al. 1990; Clark and Wolffe 1991). If chromatin assembly on replicating DNA is more repressive than that on duplex DNA, we might expect to find the promoter region on a duplex template that is assembled into chromatin (independent of DNA synthesis) much more accessible to restriction enzymes than the promoter regions of an initially single-stranded template that has undergone complementary strand synthesis coupled to chromatin assembly. This possibility was tested using the scheme outlined in Figure 5.

The construct containing the CMV promoter has two cleavage sites for the restriction endonuclease SstI (Fig. 5A). One site of cleavage (B cut) is adjacent to the TATA homology of the promoter [at -13 relative to the start site of transcription $(+1)]$; the other site of cleavage (A cut) is in a vector region downstream of the transcription unit. To determine the proportion of cleavage at one site versus the other, a second restriction endonuclease (HindIII) cutting the M13 construct only once was used. A scheme of the expected results in various situations is shown in Figure 5A. Experimental results are shown in Figure 5B.

Naked DNA controls show that the vector sequence (A cut) and promoter region (B cut) are equally accessible to the restriction enzyme [Fig. 5B, control, cf. lane D (cut with SstI alone) with lane I (cut with SstI and HindIII)]. After DNA has been injected into the oocyte nucleus, the resultant minichromosomes are less accessible to the enzyme than naked DNA /cf. lanes D, control, ss, and $\mathrm{ds}$ ) consistent with nucleosome assembly. We find that within duplex DNA assembled into chromatin in the oocyte nucleus, the promoter (B cut) is more accessible than the vector (A cut) (Fig. 5B, dsDNA). In contrast, the replicated DNA does not show any preferential accessibility (Fig. 5B, ssDNA). This difference might reflect the assembly of the basal transcriptional machinery over the promoter on the double-stranded template, thereby excluding histones or proper chromatin formation (see later). Therefore, the differential accessibility of the promoter DNA in templates initially injected as ssDNA or dsDNA correlates with their respective transcriptional activity and reveals a locally different structural organization. We then wished to explore the basis of this selective repression associated with chromatin assembly on replicating DNA.

\section{Replication-mediated repression requires DNA synthesis across the basal promoter elements of the gene}

We then examine whether replication-mediated repression is a long-range effect that only requires the association of the replication machinery somewhere on the template or a local effect that actually requires DNA synthesis over the promoter. Our approach is to make templates that are partially single stranded and partially double stranded. The chromatin assembly and transcriptional properties of these templates are examined after injection into the oocyte nucleus.

The procedure that we use to generate the partial duplexes is illustrated schematically in Figure 6A. The M13 universal primer is hybridized to single-stranded M13 constructs containing the CMV promoter fused to the CAT gene. The primer is then extended in vitro using the Klenow fragment of bacterial DNA polymerase to render varying amounts of the single-stranded template into the double-stranded form. The length of the duplex DNA is assessed by including a small amount of $\left[\alpha-{ }^{32} \mathrm{P}\right] \mathrm{dATP}$ and examining the extension products by alkaline agarose gel electrophoresis. As can be seen (Fig. $6 \mathrm{~B}$ ), the extension products cover a distribution of sizes ranging from $\sim 500$ nucleotides (including the promoter) to $>2000$ nucleotides (including the promoter and CAT genel.

To control for the stability of the partial duplexes following injection into oocyte nuclei, we use templates with short radiolabeled duplex $(\sim 500$ nucleotide) regions. We find that the conversion of the partial duplex into a completely duplex template readily occurs but, surprisingly, is no more efficient than following the injection of a purely single-stranded template (Fig. $6 \mathrm{C}$ ). Supercoiled dsDNA is detected $2 \mathrm{hr}$ after injection into the oocyte nucleus. Quantitation of the efficiency of conversion of partial to complete dsDNA indicates that half of the injected partial duplexes are stable and converted to a double-stranded form (Fig. 6C; data not shown). Thus, a substantial fraction of the injected template initially 

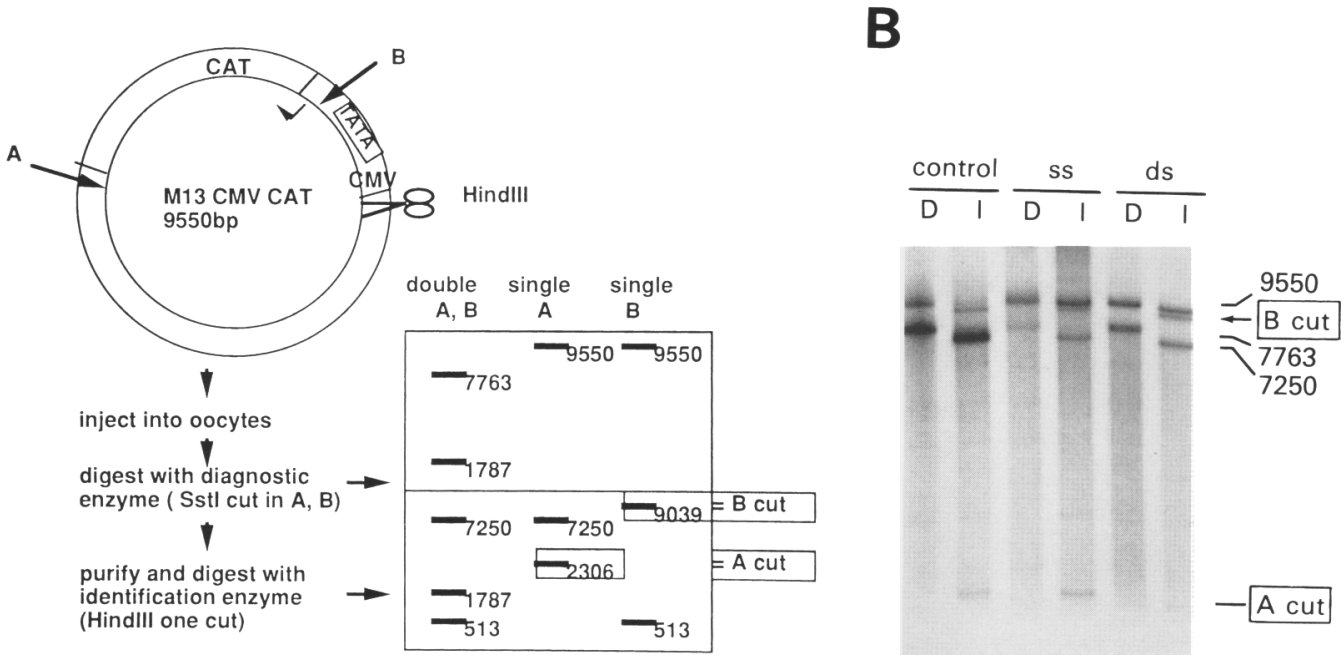

Figure 5. Restriction enzyme sensitivity in the promoter vs. the vector region; comparison of the replicated vs. nonreplicated template as chromatin. $(A)$ A scheme of the experiment is presented. A group of 10 oocytes was injected with the DNA template and incubated for $18 \mathrm{hr}$. They were then resuspended in restriction enzyme buffer with the diagnostic enzyme (SstI) that cuts two sites, $A$ and $B$, in the plasmid, as indicated. DNA is then purified and half of the material processed for a secondary digestion using the identification enzyme (HindIII) that produces a single cut in the plasmid, as indicated. The size of the fragments obtained under the various digestion conditions is schematically indicated. The 2306-bp fragment is characteristic of a single cut at $\mathrm{A}$. The 9030-bp fragment is characteristic of a single cut at B in the promoter region (site - 13). (B) Experimental results. The experiment was done using as control a double-stranded DNA labeled in vitro mixed with a homogenate of 10 oocytes in restriction enzyme buffer with the enzyme SstI (400 units) for $30 \mathrm{~min}$ at $37^{\circ} \mathrm{C}$. This amount of enzyme was determined to give a complete digestion after $1 \mathrm{hr}$ at $37^{\circ} \mathrm{C}$. The 30-min time point gives an intermediate in the digestion kinetics where predominantly single cuts have occurred, which enables the ratio of cutting at site A vs. site B to be assessed. Single-stranded DNA was injected, together with $\left[\alpha-{ }^{32} \mathrm{P}\right] \mathrm{dATP}$, into oocyte nuclei and incubated further for $18 \mathrm{hr}$. A group of 10 healthy oocytes was collected, and minichromosomes were isolated and incubated with the restriction enzyme $S s t \mathrm{I}(400 \mathrm{units})$ for $1 \mathrm{hr}$ at $37^{\circ} \mathrm{C}$. dsDNA labeled in vitro was injected in a similar way, and the minichromosomes were collected and treated as for ssDNA. Purified DNA after the first diagnostic digestion $(D)$ is submitted to electrophoresis on a $0.8 \%$ agarose gel in TAE buffer in parallel with the products of the secondary digestion with the identification enzyme HindIII (I). The position of the various restriction fragments is indicated. Note that undigested DNA (supercoiled form I) on this gel migrates at the same position as linearized DNA in lanes $D$ and will account for the linear full-length fragment recovered after the secondary cut in lanes $I$. Quantitation of the intensity of the bands was undertaken by densitometric scanning (not shown).

present as partial duplexes is converted to the transcriptionally competent duplex form. This is sufficient to examine the consequences for transcription.

Our next experiments examine the efficiency of the transcription of injected templates that are initially partial duplexes. For comparison, double-stranded and single-stranded templates are injected and examined for chromatin assembly and transcription. We find that the partial duplexes are transcribed $\sim 10$ times more efficiently than the initially single-stranded template and 3 times less efficiently than the double-stranded template (Fig. 7A). The latter effect could be attributable to some destabilization of the partial duplex. The size distribution of partial duplex molecules injected into oocyte nuclei at the beginning of the experiment is shown (Fig. 7B), together with recovery of DNA at the end of the experiment (16 hr) (Fig. 7C), at which time transcript accumulation (Fig. 7A) is assessed. The final amount of dsDNA resulting from the injection of initially partial duplex templates will reflect both DNA synthesis on stable partial duplexes and also some synthesis on single-stranded templates from destabilized duplexes (Fig. $7 \mathrm{C}$ ). The table in Figure 7 (below $A$ ) quantitates the relative transcription efficiency after normalization for final dsDNA content. However, the values indicated do not take into account the different stability of the various duplexes. There is a clear potentiation of transcription following the injection of partial duplexes, including $\sim 1 \mathrm{~kb}$ of the promoter region over initially single-stranded templates. In contrast, when a primer is used to generate partial duplexes that begin downstream of the CMV promoter (using the M13 17-base probe primer from GIBCO BRL, Gaithersburg, $M D$ |, the partial duplex has low transcriptional activity comparable with those observed after microinjection of ssDNA, even for the longest duplex generated $(\sim 5 \mathrm{~kb})$ (Fig. 8). In this experiment, three different partial duplex lengths are used (Fig. 8B, 1, 1', and 1", corresponding to average lengths of 500,2500 , and 5000 $\mathrm{bp}$ ), and transcription from an internal dsDNA control is also shown $\left(\mathrm{H}^{\circ} \%\right.$. We conclude that to potentiate transcription from a partial duplex, the double-stranded region must include the promoter. 
Figure 6. Characterization and fate of partial (hemi) duplexes after injection into oocyte nuclei. $(A)$ A scheme is presented for the preparation of various partial duplexes. The universal primer for M13 sequencing has been annealed with the ssDNA containing the CMV promoter in front of the CAT gene (SSM13 CMV CAT). Extension was performed using the Klenow fragment from $E$. coli DNA polymerase for various times at room temperature. The major products are represented schematically. $(B)$ The hemiduplexes were prepared by extension in the presence of $\left[\alpha-{ }^{32}\right.$ P]dATP to label the newly synthesized complementary strand. The extension was for $15 \mathrm{~min}$ (lane 1), $30 \mathrm{~min}$ (lane 2), $1 \mathrm{hr}$ (lane 3), and $2 \mathrm{hr}$ (lane 4). The average length of the extension product is analyzed by electrophoresis in a $1 \%$ alkaline agarose gel. Markers are from an SstIHindIII digestion of dsDNA labeled in vitro, using a single-stranded template in the Xenopus egg extract so as to label the minus strand only (see Materials and methods). (C) Labeled small partial duplexes, $\sim 500$ bp in length (corresponding to the products analyzed in $B$, lane 1 ), were injected into oocytes and incubated for various times (as indicated). DNA is isolated and analyzed by electrophoresis on a $1 \%$ agarose gel in TAE buffer. The resulting autoradiograph is shown. The positions of double-stranded form I, form II, form Ir, form III, and duplex are indicated. $C$ is a dsDNA labeled in vitro as a control.
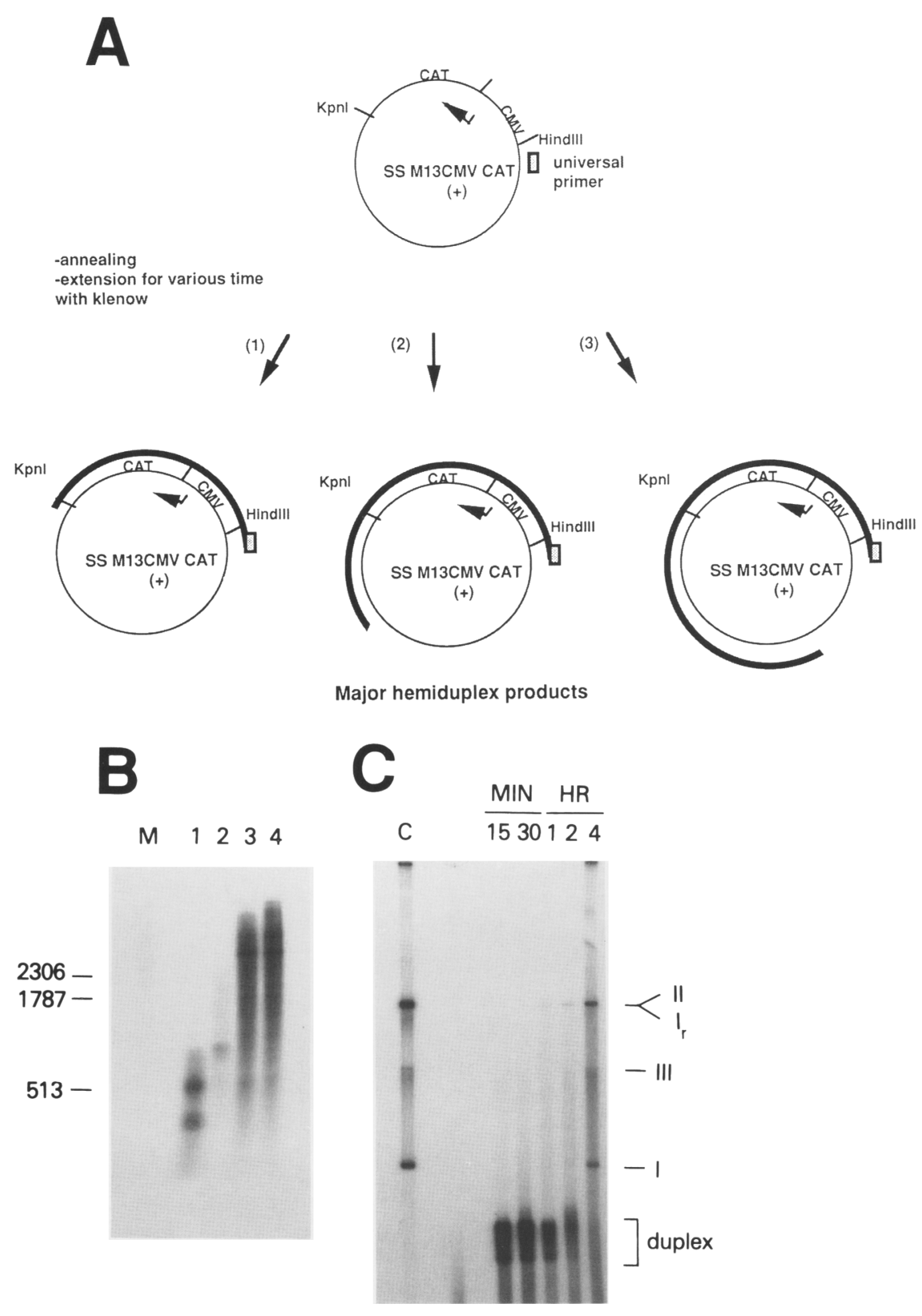

To determine which part of the promoter was important to obtain transcription from a partial duplex, we used different primers, as shown schematically (Fig. 8A). Partial duplexes were synthesized, and a transcription and replication analysis was undertaken, as described previously in Figure 7. Transcription assays demonstrate that the partial duplexes including the basal promoter consisting of the TATA box were sufficient to obtain maximal transcription (cf. CMV transcription in Fig. 8B, $1,1^{\prime}$, and $1^{\prime \prime}$, with Fig. $8 \mathrm{C}, 2$ and 3 ). This suggests that the transcription that we observe on the double-stranded CMV construct is not regulated by the upstream elements and is attributable solely to the basal transcription machinery. Consistent with this observation is the use of double-stranded templates with various deletions in the upstream regulatory region of the $\mathrm{H}^{\circ}$ promoter which indicated that only a minimal region including the basal elements is required for maximal transcription in oocyte nuclei (not shown). It is also important to note that the histone $\mathrm{Hl}^{\circ}$ gene is not expressed from the endogenous oocyte chromosome (Khochbin and Wolffe 1993).

We interpret these experiments to indicate that the repressive influence on transcription attributed to replication of DNA ( $>30$-fold for the CMV promoter) is predominantly attributable to local effects coupling chromatin assembly with DNA synthesis over the basal elements of the promoter of the gene of interest. 

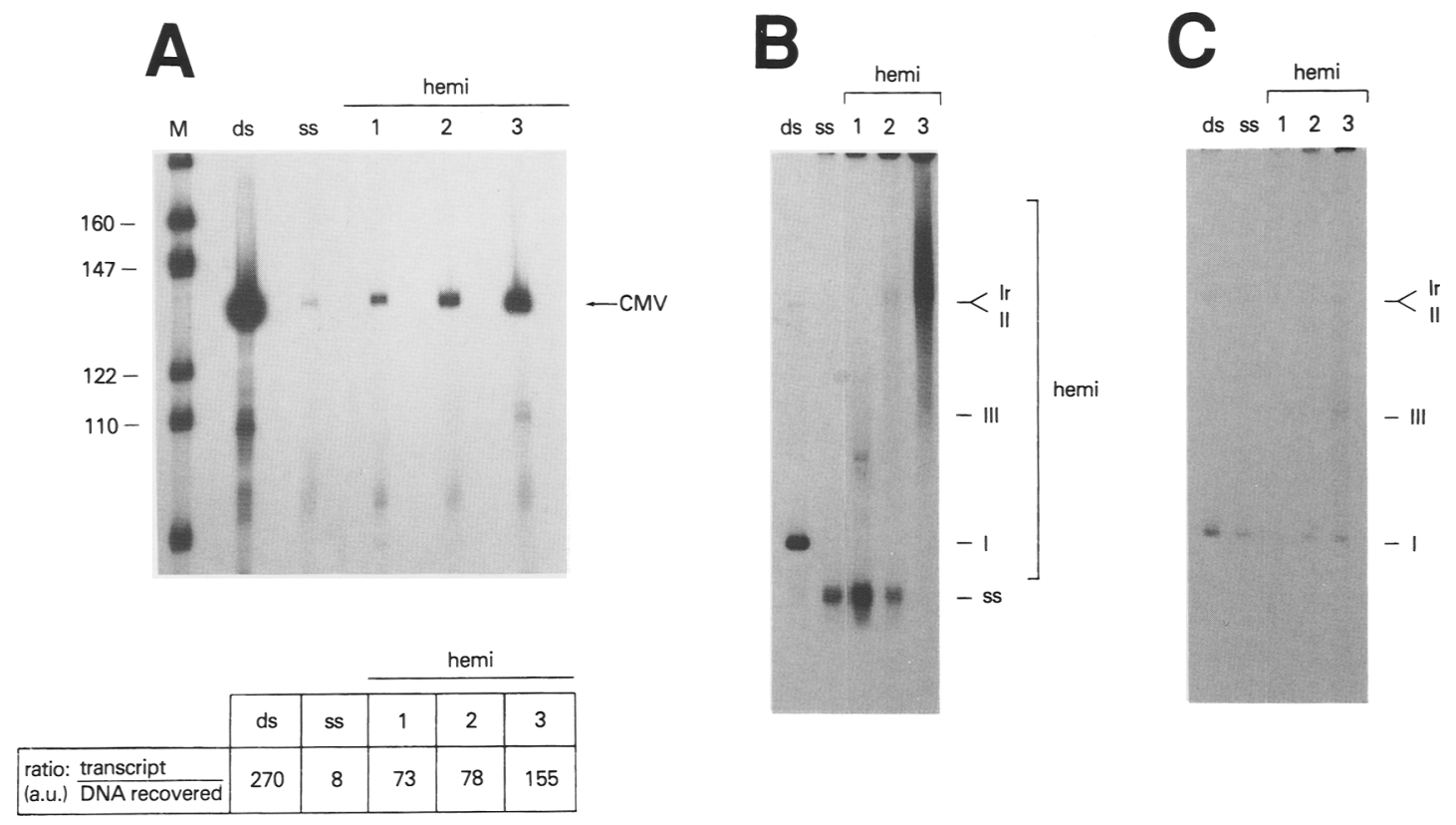

Figure 7. Partial duplexes covering the promoter and gene region permit more efficient transcription after microinjection into the nuclei of oocytes than does a ssDNA template. $(A)$ Transcription obtained from the various templates was analyzed by primer extension. The specific extension product is indicated by an arrow. The partial duplexes used correspond to various extension times from the universal primer with the Klenow fragment as follows: $30 \mathrm{~min}$ (lane 1), $2 \mathrm{hr}$ (lane 2), $16 \mathrm{hr}$ (lane 3). The marker is a pBR322 HpaII digest. The table (bottom) gives the amount of transcript normalized to the amount of DNA in arbitrary units (a.u.) recovered from the injection experiment. Quantitation is performed by densitometric scanning of the autoradiographs (using various exposures to compare values in a linear range) corresponding to the transcription assay shown in $A$ and the DNA blot shown in $C$, respectively. $(B)$ The various DNA solutions for injection were analyzed by electrophoresis on $1 \%$ agarose gel in TAE buffer, blotted and hybridized with a random primed labeled probe to check for the amount of ssDNA remaining after preparation of the partial duplexes (lanes 1-3 as in $A) .(C)$ Part of the material obtained from the injection experiment in $A$ was analyzed by electrophoresis on a $1 \%$ agarose gel to determine the recovery of dsDNA. Gels were processed as in B. Forms I (closed circular supercoiled), II (nicked circular), Ir (closed circular relaxed), and III (linear) and ssDNA (ss) and partial duplexes (hemi) are indicated.

\section{Gal4-VP16 is a dominant activator of transcription regardless of the pathway of chromatin assembly}

We wished to examine whether the chromatin assembly coupled to replication would permit the activation of transcription by a specific activator. We chose a simple model template with a minimal promoter from the adenovirus E4 gene and five consensus upstream binding sites for the Gal4 protein, a template that has already been well characterized (Carey et al. 1990; Laybourn and Kadonaga 1991). The activator used was the chimeric protein Gal4-VP16, which has been shown to be a strong activator of transcription in vivo and in vitro (Sadowski et al. 1988; Chasman et al. 1989). The experimental protocol (Fig. 9A) was to microinject single-stranded or double-stranded templates into oocyte nuclei either with (early) or without (none) the activator and to examine transcription. The addition of the activator was either early, in which case the DNA was mixed with the protein before injection, or late, in which case the DNA template was first injected and allowed to assemble into chromatin for $4 \mathrm{hr}$ before the activator was injected. In the absence of activator, we find that the doublestranded template is transcribed more efficiently than the single-stranded template injected into the oocyte consistent with the results with the $\mathrm{H}^{\circ}$ and CMV promoters (Figs. 1, 3, 7, and 8) (Fig. 9B, none). Surprisingly, transcriptional activation by Gal4-VP16 is obtained on the replicating template, as well as on the nonreplicating template, independent of the pathway of chromatin assembly (Fig. 9B, late). This activation depends on the presence of the VP16 activation domain, because deletion of this domain prevents transcriptional activation (Fig. 10A) and on the presence of the binding sites for Gal4-VP16, as constructs without these sites displayed only a limited transcriptional activation in the presence of the protein (Fig. 10B). Remarkably, the extent of activation obtained is high, reaching levels comparable with those seen in vivo (Sadowski et al. 1988; Majumder et al. 1993). The total level of activation with the singlestranded template (150-fold) is higher than for the double-stranded template (30-fold), although the final level of activated transcription is approximately the same. This probably reflects the fact that in the absence of the activator, basal transcription is higher for the microinjected nonreplicated duplex template assembled into chromatin compared with the replicating singlestranded template assembled into chromatin (Fig. 9B, none, cf. ds and ss). We conclude that chromatin-mediated repression driven though its coupling to DNA syn- 

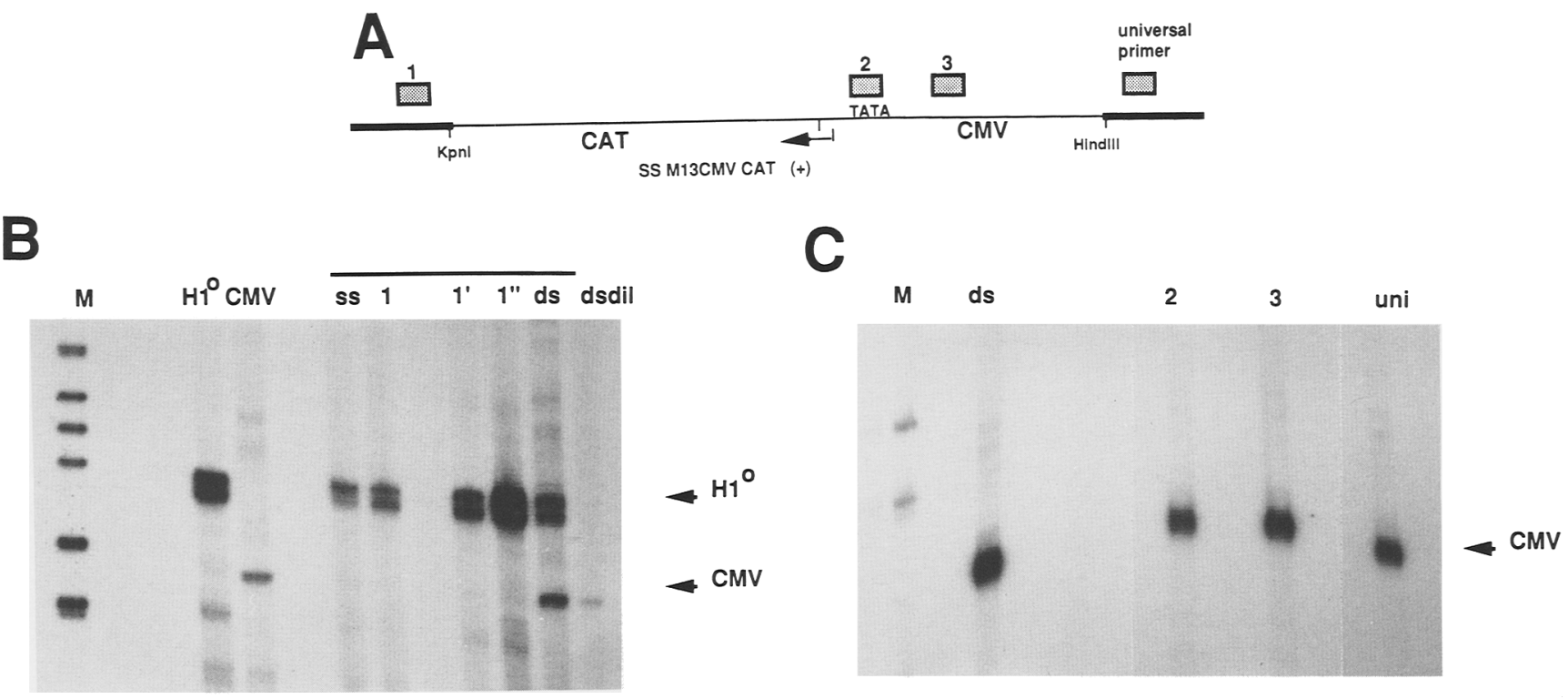

Figure 8. To overcome repression by partial duplex formation, the duplex region must cover the basal elements of the promoter. $(A)$ A scheme shows the location of the various primers used to make partial duplexes with a single-stranded CMV construct (Materials and methods). Partial duplexes were made and analyzed as described in Materials and methods and in the legend to Fig. 6. (B) Partial duplexes were made using the CMV CAT M13 ssDNA after extension in vitro with the Klenow fragment from the primer 1 downstream of the CAT gene for various times: (1) $15 \mathrm{~min}_{;}\left(1^{\prime}\right) 1 \mathrm{hr} ;\left(1^{\prime \prime}\right) 3 \mathrm{hr}$. The average length of the duplex region was sized on an alkaline gel and gave $\sim 500 \mathrm{bp}(1), 2.5 \mathrm{~kb}\left(1^{\prime}\right)$, and $5 \mathrm{~kb}\left(1^{\prime \prime}\right)$. This partial duplex was injected into nuclei of oocytes together with a double-stranded $\mathrm{H}^{\circ}$ promoter containing template as an internal control for recovery. The dsdil lane contained one-tenth the normal concentration of dsDNA (CMV). After $18 \mathrm{hr}$ of incubation the oocytes were processed for RNA preparation, and transcription analysis was undertaken as described by primer extension (Materials and methods). The positions corresponding to the correct initiation of transcripts on the $\mathrm{Hl}^{\circ}$ promoter and CMV promoter are indicated by arrows. $(C)$ Partial duplexes were made using the CMV CAT M13 ssDNA after extension with the Klenow fragment for $3 \mathrm{hr}$ with different primers as indicated $(2,3$, uni). The average length of the duplex region $(\sim 5 \mathrm{~kb})$ was similar in the three cases (not shown). Transcription analysis was undertaken, and DNA recovery was determined (Materials and methods). Primer extension analysis is shown. The correct extension product is indicated (CMV).

thesis can be overcome in the presence of a trans-activator to give rise to a full activation of the template. It is remarkable that the final level of transcription upon activation by Gal4-VP16 is comparable whether the activator is prebound to its target site or added after chromatin assembly is completed.

We then considered the possibility that only a small fraction of the molecules effectively bind the activator and give rise to the transcription level found in the activated state. Under these circumstances, a small fraction of the templates could be improperly assembled into nucleosomes and retain the capacity to interact with the activator. To examine this possibility, the binding of Gal4-VP16 to the template was investigated through DNase I footprinting in vivo. In this assay, detection of a footprint over the Gal4-binding sites requires that the vast majority of the molecules interact stably with the activator. Binding of Gal4-VP16 can be detected for the double- or the single-stranded templates after assembly into chromatin (Fig. 11). Consequently, Gal4-VP16 is likely to act on the majority of chromatin templates and not on a minor fraction of non-nucleosomal DNA molecules. In the absence of activator (Fig. 11, lanes -, ds, and ss) the DNase I cleavage pattern does not display a 10-bp modulation; thus, no specific nucleosome posi- tioning can be detected or appears to be required for Gal4 binding. Association of the activator with DNA requires only the DNA-binding domain moiety of the Gal4 protein expressed within the mutant protein Gal4 (1-94) (Lin et al. 1988). This indicates that although the activation domain (VP16) is required to activate transcription (Fig. 10A), it is not necessary for stable binding of the Gal4 domain on chromatin.

\section{Discussion}

\section{Chromatin assembly coupled to replication, a mechanism to establish basal repression}

The chromatin assembly process coupled to DNA synthesis in the Xenopus oocyte nucleus is significantly more repressive toward basal transcription than chromatin assembly on duplex DNA (Figs. 1, 3, 4, 7-9). Chromatin structure and DNA topology have been previously proposed to influence the transcription of class III and class II genes microinjected into the Xenopus oocyte nucleus as dsDNA (Harland et al. 1983; Weintraub 1985). The circularity of the template is critical, as linear templates $(\sim 3 \mathrm{~kb}$ in size) containing promoters for genes 


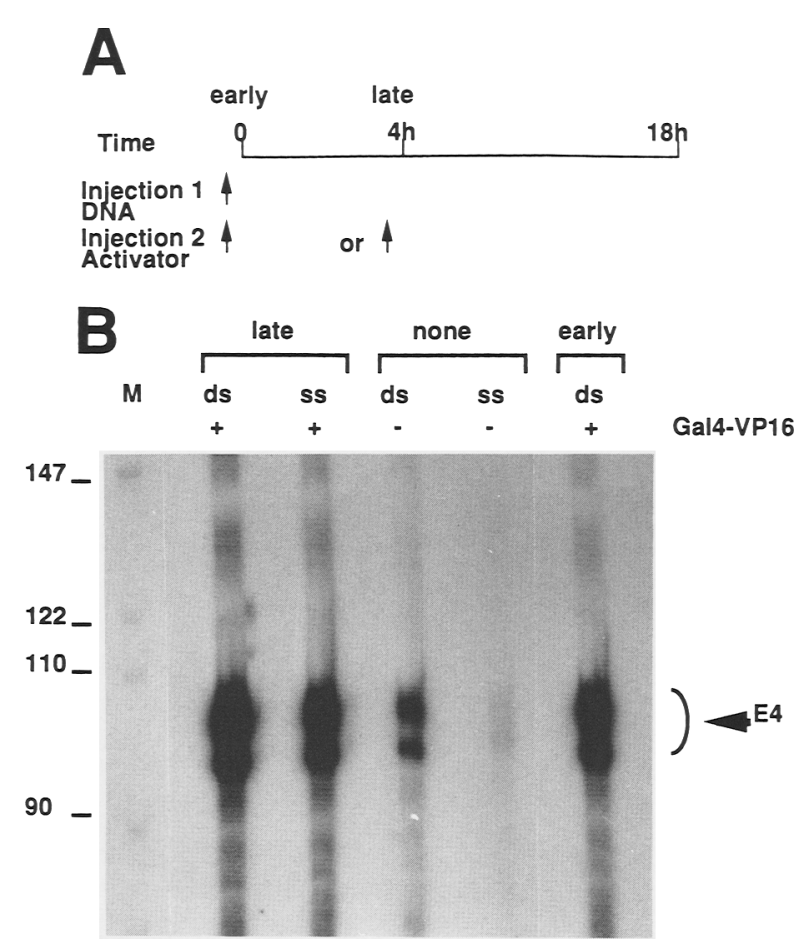

Figure 9. The Gal4-VP16 transcription activator can stimulate transcription on templates assembled in chromatin regardless of assembly pathway. $(A)$ The injection procedure followed the two-step protocol as shown on the scheme. At $t=0$, the DNA template was injected. The addition of the activator was either early, by mixing the protein with the DNA solution before injection, or late after chromatin assembly by a second injection of the protein $4 \mathrm{hr}$ after the initial injection of DNA. At this time double-stranded or single-stranded templates are fully assembled into chromatin (Fig. 2). Each oocyte was injected with $30 \mathrm{nl}$ of solution containing the DNA template $(200$ $\mathrm{ng} / \mu \mathrm{l})$. The specific activator was injected as described above in approximately fourfold molar excess over binding sites (each promoter binds five Gal4 dimers). The Gal4 derivatives were bacterially expressed (Carey et al. 1990; Lin and Green 1990). About 30 oocytes were injected for each sample, and transcripts were allowed to accumulate for $18 \mathrm{hr}$ at $18^{\circ} \mathrm{C}$. Only healthy oocytes were collected and homogenized. One fraction of the sample was processed for DNA purification, gel analysis, and blotting to check recovery and state of the template (not shown). Another fraction was processed for RNA purification and analyzed by the primer extension method. A 28-mer encompassing region +72 to +100 of the $\mathrm{E} 4$ gene was used. Primer extension gives rise to a major product of 100 nucleotides. $(B)$ Transcription analysis on the E4 constructs, injected as double-stranded (ds) or single-stranded (ss) form, either without the activator $(-$, none), or with the activator added $(+)$, early or late, as indicated.

transcribed by RNA polymerase II are weakly transcribed compared with circular templates (Mertz 1982; Harland et al. 1983; data not shown). In our experiments the vast majority of our templates are always circular. Preformation of nucleosome cores on DNA before microinjection was found previously to inhibit transcription (Weisbrod et al. 1982; Gargiulo et al. 1984). Remark- ably however, chromatin assembly using dsDNA templates, when occurring in the oocyte nucleus, has never been found to efficiently repress basal transcription from either class III or class II genes (Miller and Mertz 1982; Weisbrod et al. 1982; Gargiulo and Worcel 1983; Gargiulo et al. 1984). Our results therefore provide the first evidence that chromatin assembly can actually be repressive in the Xenopus oocyte nucleus. The key contributory factor in generating the repressed state appears to be replication-coupled chromatin assembly.

As templates that are initially either single or double stranded are both assembled into chromatin in the oocyte nucleus (Fig. 2), we infer that the important variable in determining basal gene activity is the pathway of chromatin assembly (Figs. 4 and 5; Fotedar and Roberts 1989; Smith and Stillman 1989|. Chromatin-mediated repression of basal transcription can be attributed to either the prevention of complete preinitiation complex assembly (Workman et al. 1988; Almouzni et al. 1990a, 1991) or to chromatin-mediated DNA-folding events that prevent RNA polymerase from gaining access to the preinitiation complex (Almouzni et al. 1990a, 1991; Chipev and Wolffe 1992; Hansen and Wolffe 1992). The latter effect might account for the transient nature of RNA polymerase II transcription on the replicating templates (Fig. 3). It is also possible that chromatin assembly on replicating DNA uses a distinct molecular mechanism to that on duplex DNA and that these differences influence basal transcription machinery access to the promoter (Almouzni et al. 1990b; Gruss et al. 1990). The DNA synthetic process itself does not exert a transmissible repressive effect on transcription. For repression of transcription to occur, second-strand synthesis must include the promoter to be repressed, indicating that replication-dependent events involved in repressing transcription act locally in cis (Figs. 7 and 8 ).

We suggest that this replication-coupled mechanism might be important for establishing the repression of basal transcription in the cell (Grunstein 1990). It is probable that the coupling of chromatin assembly to the replication process more accurately reflects the physiological process in vivo leading to general repression of basal class II gene transcription. This observation provides an explanation for the chromatin-mediated repression of transcription on replicating episomes but the absence of such repression on transiently transfected nonreplicating DNA (Archer et al. 1992).

The repression of basal transcription found following chromatin assembly coupled to replication appears not to represent an irreversible pathway, as the concurrent or subsequent addition of a specific activator, Gal4-VP16, allows the activation of transcription to levels comparable with those obtained on nonreplicated templates (Fig. 9; see also Archer et al. 1992). Therefore, the repressive nature of chromatin assembled during replication may represent a default state whereby most genes will be inactivated and repressed if sequence-specific trans-activators or antirepressors (Workman et al. 1988, 1990; Croston et al. 1991) are not available. Moreover, the present study allows us to define a dominant role for the 
Figure 10. The VP16 activation domain of Gal4-VP16 and Gal4-binding sites are required for effective activation of transcription from chromatin templates in vivo. The injection procedure used the early addition protocol with a double-stranded template illustrated in Fig. 9A and described in the legend to Fig. 9. (A) Various Gal4 derivatives (Carey et al. 1990; Lin and Green 1990) were examined for their capacity to activate transcription: (Lane 1) No addition; (lane 2) Gal4-VP16; (lane 3) Gal4 (1-147); (lane 4) Gal4 (1-94); (lane 5) Gal4-AH. The correctly initiated transcript is indicated by the arrow. (B) Transcriptional activation by Gal4-VP16 from the E4 promoter fused to five Gal4-binding sites (G5) or to zero sites (G0). Fold transcriptional activation in the presence of Gal4-VP16 (+) compared with its absence $(-)$ is indicated.

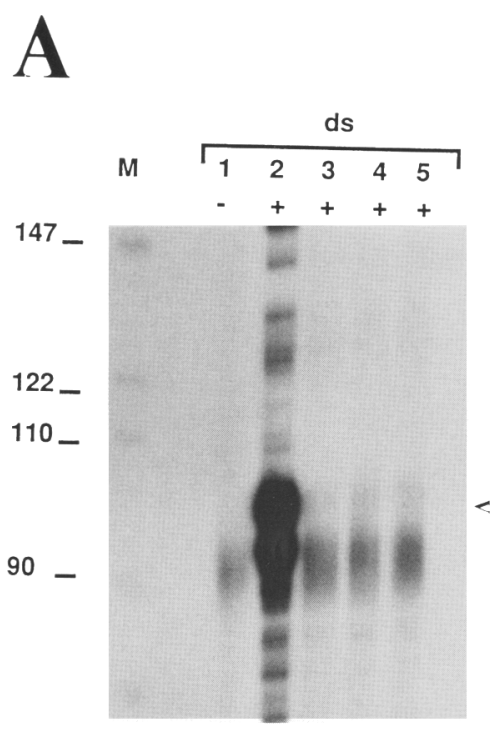

B

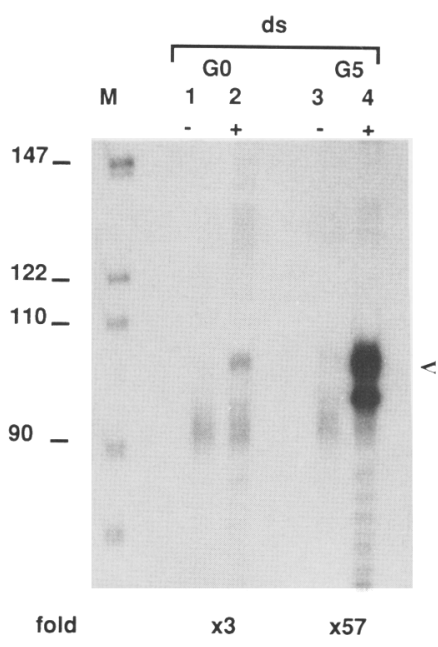

ence of the activator occurs at similar levels (Fig. 9B). Thus, the activator can gain access to its target sites in the minichromosomes in vivo as it does on reconstituted core particles (Taylor et al. 1991; Workman and Kingston 1992) and then exert its activation function probably by both overriding chromatin-repressive effects and through direct interactions with the basal transcription machinery (Stringer et al. 1990). These effects could be directly mediated by the activator or might involve intermediate coactivators (Lin and Green 1990). As many regulatory DNA elements contain multiple activatorbinding sites, it has been suggested that activators could fall into a hierarchy; Gal4 is clearly a primary dominant activator that can interact directly with chromatin and set off a process that facilitates the binding of other proteins to the chromatin template.

\section{Chromatin assembly and gene expression in the nucleus of the Xenopus oocyte}

Xenopus oocytes arrested in prophase of meiosis will replicate single-stranded but not dsDNA templates /Graham et al. 1966; Gurdon 1968; Harland and Laskey 1980 ). We have made use of this property to unambiguously distinguish between newly synthesized dsDNA and unreplicated dsDNA. Thus, we resolve two pathways for chromatin assembly (Fig. 2). One pathway is independent of DNA synthesis; the other is dependent on DNA synthesis. The remarkable efficiency of the oocyte nucleus to convert ssDNA to duplex templates, to assemble chromatin, and to transcribe (Gurdon and Wickens 1983; Gurdon and Wakefield 1986) allows the impact of these different processes on each other to be experimentally assessed. Because complementary strand synthesis on single-stranded templates in the oocyte is a simplified system, which most likely utilizes the enzymatic machinery found on the lagging strand of the rep- 
lication fork (Méchali and Harland 1982), it will also be of interest to examine the influence of chromatin assembly on transcription following the genuine replication of dsDNA in Xenopus eggs (Harland and Laskey 1980). Experiments with both somatic cell extracts and oocyte or egg extracts have each shown that replication can promote chromatin assembly (Stillman 1986; Almouzni and Méchali 1988). Thus, common mechanisms must be shared, and future experiments should permit the comparison of their impact on transcription. Analogous systems to the one described here should provide further insights into the impact of replication on both chromatin structure and the transcription process and thereby help to elucidate the mechanism and time of action of transcriptional activators.

\section{Materials and methods}

\section{DNA preparation and constructs}

Single-stranded DNA from bacteriophage M13 mp18 is prepared from phage purified by $\mathrm{CsCl}$ buoyant density centrifugation. Double-stranded supercoiled form I M13 derivatives are isolated and prepared as described (Maniatis et al. 1982). DNA solutions are in injection buffer $(88 \mathrm{~mm} \mathrm{NaCl}, 15 \mathrm{~mm}$ HEPES-KOH at $\mathrm{pH}$ 7.6). The concentration of DNA microinjected into oocyte nuclei is adjusted so as to obtain maximal chromatin assembly (see Gargiulo and Worcel 1983) and to be in the linear range for transcription as a function of the amount of template /data not shown; Gurdon and Melton 1981).

Radiolabeled dsDNA is prepared using a single-stranded M13 DNA and Xenopus egg extract as described by Almouzni and Méchali (1988). This procedure gives rise to random incorporation of radioactive nucleotides during complementary strand synthesis.

Various clones were used for the microinjection experiments as described below. The promoter from the immediate early gene 1 from the human CMV driving transcription of the chloramphenicol acetyl transferase gene (CAT gene) as a HindIIIKpnI fragment from the human CMV clone 101 (kindly provided by Dr. Lothar Hennighausen, NIDDK, National Institutes of Health, Bethesda, MD) was inserted into the linker region of M13 mp18 (designated M13 CMV CAT). The promoter from the Xenopus histone $\mathrm{H} 1^{\circ}$ gene as a HindIII-Sall fragment (Khochbin and Wolffe 1993) is inserted into the same site (designated M13 $\mathrm{H} 1^{\circ}$ ). The Ml3 construct without Gal4-binding sites containing the adenovirus E4 promoter was obtained by insertion of a XbaI-KpnI fragment from plasmid pG5E4T (Carey et al. 1990) into the corresponding sites into M13 mpl8. For the construct with the five Gal4-binding sites, a KpnI-HindIII fragment from the same plasmid was inserted into the corresponding sites into M13 mpl8.

\section{Injection and sample preparation}

The procedure was essentially as described by Gurdon and Wakefield (1986). Briefly, ovarian tissue is surgically removed from mature female Xenopus laevis anesthetized on ice. Defollication of the oocytes to facilitate microinjection is by incubation in $\mathrm{Ca}^{2+}$-free OR-2 medium containing $0.2 \%$ collagenase (Sigma) for $2 \mathrm{hr}$ at $22^{\circ} \mathrm{C}$ before gentle rinsing with modified Barth medium supplemented with $10 \mu \mathrm{g} / \mathrm{ml}$ of penicillin and 5 $\mu \mathrm{g} / \mathrm{ml}$ of streptomycin. Stage VI oocytes are selected for injec- tion. Injections are into the oocyte nucleus using a Drummond Nanoject automatic injector. The DNA or bacterially expressed, purified trans-activator Gal4-VP16 (Carey et al. 1990; Lin and Green 1990) to be injected is dissolved at the desired concentration in injection buffer. Injected oocytes are incubated in modified Barth medium containing antibiotics at $18^{\circ} \mathrm{C}$. Samples of 10-20 healthy-looking oocytes are taken after the indicated incubation time and stored at $-70^{\circ} \mathrm{C}$.

Transcription analysis, DNA analysis, and DNase I footprinting

To assess the level of transcript accumulated per DNA template, the injected oocytes are collected and suspended in $20 \mathrm{~mm}$ Tris- $\mathrm{HCl}(\mathrm{pH} 8)(15 \mu \mathrm{l}$ per oocyte). Half of the sample is made up to $30 \mathrm{mM}$ EDTA, 1\% SDS, and processed for DNA analysis; the remaining sample is processed using the RNAzol TM method (TM Cinna Scientific) to isolate RNA, followed by a $\mathrm{LiCl}$ precipitation to remove glycoproteins and yolk contaminants $(\mathrm{Ma}$ niatis et al. 1982). Additional treatment with RNase-free DNase I (Boehringer, Indianapolis, IN) is performed. Generally, the RNA equivalent to one or two oocytes is analyzed for the presence of specific transcripts by primer extension (Toyoda and Wolffe 1992) on $6 \%$ polyacrylamide gels containing $8 \mathrm{M}$ urea in TBE buffer.

The primers used for analysis from the CMV promoter were a 30-mer 3'-TACCTCTTTTTTTAGTGACCTATATGGTGG-5' that hybridizes in the CAT region, an extension giving rise to a 136-nucleotide-long product following correct initiation (see Boshart et al. 1985; Toyoda and Wolffe 1992), or a different primer, 3'-GTGGCAACTATATAGGG TTACCGTAGCA-5', hybridizing in the CAT region used so as to obtain a longer extension product (160 nucleotides). The primer used for analysis from the $\mathrm{Hl}^{\circ}$ promoter was a 25-mer $3^{\prime}$-CTTCGGTAACGCTCAGTCCCGAACTG-5' that hybridizes in the noncoding region of the $\mathrm{H}^{\circ}$ gene. Extension gives rise to two major products, 175 and 180 nucleotides in length (see Khochbin and Wolffe 1993). The primer used for transcript analysis from the E4 promoter was a 28-mer 3'-CCGACTGACAATCCGACGGCCACACTTC $-5^{\prime}$ that hybridizes in the E4 gene +72 to +100 . Extension gives rise to a major product of 100 nucleotides.

For DNA analysis, the sample is treated with proteinase $\mathrm{K}$ $\{500 \mu \mathrm{g} / \mathrm{ml})$ for $\geqslant 2 \mathrm{hr}$. After deproteinization by phenol extraction and ethanol precipitation, the samples are treated with RNase A, phenol extracted, and DNA precipitated with ethanol. The samples are then subjected to agarose gel electrophoresis as indicated. When radiolabeled material is used, the gel is dried and exposed for autoradiography. Otherwise, probes are made using a random primed labeling kit (Boehringer). Blotting and hybridization are as described (Maniatis et al. 1982). Quantitation of transcripts and DNA recovery was done with a PhosphorImager (Molecular Dynamics) or by autoradiograph scanning.

For DNase I footprinting, oocytes were injected with DNA and, when appropriate, Gal4-VP16 as described above. After 18 $\mathrm{hr}$ of incubation, DNase I digestion was performed as follows: 15 oocytes were homogenized in $200 \mu$ l of buffer E (10 mM HEPES at $\mathrm{pH} 7.5,5 \%$ sucrose, $70 \mathrm{~mm} \mathrm{KCl}$ ), made up to $3 \mathrm{~mm}$ $\mathrm{MgCl}_{2}$, and 10 units of DNase I was added for $5 \mathrm{~min}$ at room temperature. The reaction was stopped by adding EDTA to 30 $\mathrm{mM}$ and SDS to $0.1 \%$ final concentration. DNA was purified for subsequent primer extension analysis as described (Shimizu et al. 1991). Labeled E4 primer (a 28-mer encompassing region +72 to +100 of the $\mathrm{E} 4$ gene) was hybridized, and extension was done using Taq polymerase (Promega). 


\section{Hemiduplex preparation}

The single-stranded form (+) of M13 CMV CAT is annealed to a radiolabeled universal primer for M13 sequencing (GIBCO $B R L)$ or other primer as indicated $(10$ pmoles $/ \mu \mathrm{g}$ of primer of ssDNA) by incubation for $15 \mathrm{~min}$ at $65^{\circ} \mathrm{C}$ and slow cooling to room temperature. Primer extension follows the addition of a mixture of dNTPs to $200 \mu \mathrm{M}$ final concentration in the presence of the Escherichia coli DNA polymerase Klenow fragment [10 units (GIBCO BRL)] $\left[\alpha^{-32} \mathrm{P}\right] \mathrm{dATP}$ is included in experiments in which radiolabeling is required. Partial duplex synthesis is undertaken by incubation at $22^{\circ} \mathrm{C}$ for various times. DNA is then purified, and the extent of duplex region is estimated by analysis on a $1 \%$ alkaline agarose gel as described (Maniatis et al. 1982).

\section{Acknowledgments}

We thank M. O'Connell, P. Mathers, and C. Schild for valuable advice on the microinjection technique. We are grateful to J. Workman for helpful suggestions on the work and for providing various Gal4-E4 constructs as double-stranded plasmid derivatives. We thank R. Kamakaka and James Kadonaga for providing M13 E4 constructs before publication as well as Gal4-VP16 protein. We thank M. Carey for providing the expression system for the Gal4-VP16 and derivative proteins, and also G. Felsenfeld, R. Morse, and R. Simpson for critical evaluation of the manuscript. We are grateful to Ms. Thuy Vo for preparing the manuscript.

The publication costs of this article were defrayed in part by payment of page charges. This article must therefore be hereby marked "advertisement" in accordance with 18 USC section 1734 solely to indicate this fact.

\section{References}

Almouzni, G. and M. Méchali. 1988. Assembly of spaced chromatin promoted by DNA synthesis in extracts from Xenopus eggs. EMBO J. 7: 665-672.

Almouzni, G., M. Méchali, and A.P. Wolffe. 1990a. Competition between transcription complex assembly and chromatin assembly on replicating DNA. EMBO /. 9: 573-582.

Almouzni, G., D. Clark, M. Méchali, and A.P. Wolffe. 1990b. Chromatin assembly on replicating DNA in vitro. Nucleic Acids Res. 18: 5767-5774.

Almouzni, G., M. Méchali, and A.P. Wolffe. 1991. Transcription complex disruption caused by a transition in chromatin structure. Mol. Cell. Biol. 11: 655-665.

Archer, T.K., P. Lefebvre, R.G. Wolford, and G.L. Hager. 1992. Transcription factor loading on the MMTV promoter: A bimodal mechanism for promoter activation. Science 255: 1573-1576.

Bonne-Andrea, C., M.L. Wong, and B.M. Alberts. 1990. In vitro replication through nucleosomes without histone displacement. Nature 343: 719-726.

Boshart, M., F. Weber, J. Gerhard, K. Dorsch-Hasler, B. Fleckenstern, and W. Schaffner. 1985. A very strong enhancer is located upstream of an immediate early gene of human cytomegalovirus. Cell 41: 521-530.

Brown, D.D. 1984. The role of stable complexes that repress and activate eukaryotic genes. Cell 37: 359-365.

Brown, D.D. and J.B. Gurdon. 1977. High fidelity transcription of 5S DNA injected into Xenopus oocytes. Proc. Natl. Acad. Sci. 74: 2064-2068.

Carey, M., J. Leatherwood, and M. Ptashne. 1990. A potent Gal4 derivative activates transcription at a distance in vitro. Sci- ence 247: 710-712.

Chasman, D.I., J. Leatherwood, M. Carey, M. Ptashne, and R.D. Kornberg. 1989. Activation of yeast polymerase II transcription by herpesvirus VP16 and Gal4 derivatives in vitro. Mol. Cell. Biol. 9: 4746-4749.

Chipev, C.C. and A.P. Wolffe. 1992. Chromosomal organization of Xenopus laevis oocyte and somatic 5S rRNA genes in vivo. Mol. Cell. Biol. 12: 45-55.

Clark, D. and A.P. Wolffe. 1991. Superhelical stress and nucleosome mediated repression of 5S RNA gene transcription in vitro. EMBO I. 10: 3419-3428.

Cortese, R., R. Harland, and D. Melton. 1980. Transcription of tRNA genes in vivo: Single stranded compared to double stranded templates. Proc. Natl. Acad. Sci. 77: 4147-4151.

Croston, G.E., L.A. Kerrigan, L.M. Lira, D.R. Marshak, and J.T. Kadonaga. 1991. Sequence specific antirepression of histone H1-mediated inhibition of basal RNA polymerase II transcription. Science 251: 643-649.

Dimitrov, S., G. Almouzni, M. Dasso, and A.P. Wolffe. 1993. Chromatin transitions during early Xenopus embryogenesis: Change in histone $\mathrm{H} 4$ acetylation and in linker histone type. Dev. Biol. (in press).

Felsenfeld, G. 1992. Chromatin as an essential part of the transcription mechanism. Nature 355: 219-224.

Fotedar, R. and J.M. Roberts. 1989. Multistep pathway for replication dependent nucleosome assembly. Proc. Natl. Acad. Sci. 86: 6459-6463.

Gargiulo, G. and A. Worcel. 1983. Analysis of the chromatin assembled in germinal vesicles of Xenopus oocytes. J. Mol. Biol. 170: 699-722.

Gargiulo, G., F. Razvi, and A. Worcel. 1984. Assembly of transcriptionally active chromatin in Xenopus oocytes requires specific DNA binding factors. Cell 38: 511-521.

Graham, C.F., K. Arms, and J.B. Gurdon. 1966. The induction of DNA synthesis in frog egg cytoplasm. Dev. Biol. 14: 349381.

Grunstein, M. 1990. Nucleosomes: Regulators of transcription. Trends Genet. 6: 395-400.

Gruss, C., C. Gutierrez, W.C. Burhans, M.L. De Pamphilis, T. Koller, and J.M. Sogo. 1990. Nucleosome assembly in mammalian cell extracts before and after DNA replication. EMBO I. 9: 2911-2922.

Gurdon, J.B. 1968. Changes in somatic cell nuclei inserted into growing and maturing amphibian oocytes. J. Embryol. Exp. Morphol. 20: 401-414.

Gurdon, J.B. and D.A. Melton, D.A. 1981. Gene transfer in amphibian eggs and oocytes. Annu. Rev. Genet. 15: 189-218.

Gurdon, J.B. and L. Wakefield. 1986. Microinjection of amphibian oocytes and eggs for the analysis of transcription. Microinjection and organelle transplantation techniques. Methods Cell Biol. 15: 270-299.

Gurdon, J.B. and M.P. Wickens. 1983. The use of Xenopus oocytes for the expression of cloned genes. Methods Enzymol. 101: 370-386.

Hansen, J. and A.P. Wolffe. 1992. Influence of chromatin folding on transcription initiation and elongation by RNA polymerase III. Biochemistry 31: 7977-7988.

Harland, R.M. and R.A. Laskey. 1980. Regulated replication of DNA microinjected into eggs of Xenopus laevis. Cell 21: 761-771.

Harland, R.M., H. Weintraub, and S.L. McKnight. 1983. Transcription of DNA injected into Xenopus oocytes is influenced by template topology. Nature 302: 38-43.

Khochbin, S. and A.P. Wolffe. 1993. Developmental regulation and butyrate inducible transcription of the Xenopus histone $\mathrm{H}^{\circ}$ promoter. Gene 128: 173-180. 
Krude, T. and R. Knippers. 1991. Transfer of nucleosomes from parental to replicated chromatin. Mol. Cell. Biol. 11: 62576267.

Laybourn, P.J. and J.T. Kadonaga. 1991. Role of nucleosomal cores and histone $\mathrm{Hl}$ in regulation of transcription by RNA polymerase II. Science 254: 238-245.

Lin Y.-S. and M.R. Green. 1990. Mechanism of action of an acidic transcriptional activator in vitro. Cell 64: 971-981.

Lin, Y.-S., M.F. Carey, M. Ptashne, and M.R. Green. 1988. Gal4 derivatives function alone and synergistically with mammalian activators in vitro. Cell 54: 659-664.

Majumder, S., M. Miranda, and M.L. DePamphilis. 1993. Analysis of gene expression in mouse preimplantation embryos demonstrates that the primary role of enhancers is to relieve repression of promoters. EMBO J. 12: 1131-1140.

Maniatis, T., E.F. Fritsch, and J. Sambrook. 1982. Molecular cloning: A laboratory manual. Cold Spring Harbor Laboratory, Cold Spring Harbor, New York.

McKnight, S.L. and R. Kingsbury. 1982. Transcriptional control signals of a eukaryotic protein coding gene. Science 217: 316-325.

Méchali, M. and R.M. Harland. 1982. DNA synthesis in a cell free system from Xenopus eggs: Priming and elongation on single stranded DNA in vitro. Cell 30: 93-101.

Mertz, J.E. 1982. Linear DNA does not form chromatin containing regularly spaced nucleosomes. Mol. Cell. Biol. 2: 16081618.

Miller, T.J. and J.E. Mertz. 1982. Template structural requirements for transcription in vivo by RNA polymerase II. Mol. Cell. Biol. 2: 1595-1607.

Miller, A.M. and K. Nasmyth. 1984. Role of DNA replication in the repression of silent mating type loci in yeast. Nature 312: $247-251$.

Morse, R. 1989. Nucleosomes inhibit both transcriptional initiation and elongation by RNA polymerase III in vitro. EMBO I. 8: 2343-2351.

Randall, S.K. and T.J. Kelly. 1992. The fate of parental nucleosomes during SV40 DNA replication. I. Biol. Chem. 267: 14259-14265.

Ryoji, M. and A. Worcel. 1984. Chromatin assembly in Xenopus oocytes: In vivo studies. Cell 37: 21-32.

Sadowski, I., J. Ma, S. Triezenberg, and M. Ptashne. 1988. Gal4VP16 is an unusually potent transcriptional activator. $\mathrm{Na}$ ture 335: 563-564.

Shimamura, A. and A. Worcel. 1989. The assembly of regularly spaced nucleosomes in the Xenopus oocyte $S 150$ is accompanied by deacetylation of histone H4. J. Biol. Chem. 264: 14524-14530.

Shimizu, M., S.Y. Roth, C. Szent-Gyorgyi, and R.T. Simpson, R.T. 1991. Nucleosomes are positioned with base pair precision adjacent to the $\alpha 2$ operator in Saccharomyces cerevisiae. EMBO J. 10: 3033-3041.

Smith, R.C., E. Dworkin-Rastl, and M.D. Dworkin. 1988. Expression of a histone $\mathrm{Hl}$ like protein is restricted to early Xenopus development. Genes \& Dev. 2: 1284-1295.

Smith, S. and B.W. Stillman. 1989. Purificiation and characterization of CAF1, a human cell factor required for chromatin assembly during DNA replication in vitro. Cell 58: 15-25.

Sogo, J.M., H. Stahl, T. Koller, and R. Knippers. 1986. Structure of replicating simian virus 40 minichromosomes. J. Mol. Biol. 189: 189-204.

Stillman, B.W. 1986. Chromatin assembly during SV40 DNA replication in vitro. Cell 45: 555-565.

Stringer, K.F., C.J. Ingles, and J. Greenblatt. 1990. Direct and selective binding of an acidic transcriptional activator domain to the TATA-box factor TFIID. Nature 345: 783-786.
Svaren, J. and R. Chalkley. 1990. The structure and assembly of active chromatin. Trends Genet. 6: 52-56.

Taylor, I.C.A., J.L. Workman, T.J. Schmetz, and R.E. Kingston. 1991. Facilitated binding of Gal4 and heat shock factor to nucleosomal templates: Differential function of DNA-binding domain. Genes \& Dev. 5: 1285-1298.

Toyoda, T. and A.P. Wolffe. 1992. Characterization of RNA polymerase II-dependent transcription in Xenopus extracts. Dev. Biol. 153: 150-157.

Weintraub, H. 1985. Assembly and propagation of repressed and derepressed chromosomal states. Cell 42: 7905-7911.

Weisbrod, S., M.P. Wickens, S. Whytock, and J.B. Gurdon. 1982. Active chromatin of oocytes injected with somatic nuclei or cloned DNA. Dev. Biol. 94: 216-229.

Wolffe, A.P. 1991. Implications of DNA replication for eukaryotic gene expression. J. Cell. Sci. 9: 201-206.

Wolffe, A.P. and D.D. Brown. 1986. DNA replication in vitro erases a Xenopus 5S RNA gene transcription complex. Cell 47: 217-227.

Worcel, A., S. Han, and M.L. Wong. 1978. Assembly of newly replicated chromatin. Cell 15: 969-977.

Workman, J.L. and R.E. Kingston. 1992. Nucleosome core displacement in vitro via a metastable transcription factor/nucleosome complex. Science 258: 1780-1784.

Workman, I.L., S.M. Abmayr, W.A. Cromlish, and R.G. Roeder. 1988. Transcriptional regulation by the immediate early protein of pseudorabies virus during in vitro chromatin assembly. Cell 55: 211-219.

Workman, J.L., R.G. Roeder, and R.E. Kingston. 1990. An upstream transcription factor, USF (MLTF), facilitates the formation of preinitiation complexes during in vitro chromatin assembly. EMBO J. 9: 1299-1308.

Wyllie, A.H., J.B. Gurdon, and J. Price. 1977. Nuclear localization of an oocyte component required for the stability of injected DNA. Nature 268: 150-152.

Wyllie, A.H., R.A. Laskey, J. Finch, and J.B. Gurdon. 1978. Selective DNA conservation and chromatin assembly after injection of SV40 into Xenopus oocytes. Dev. Biol. 64: 178188.

Young, D. and D. Carroll. 1983. Regular arrangement of nucleosomes on 5S rRNA genes in Xenopus laevis. Mol. Cell. Biol. 3: $720-730$. 


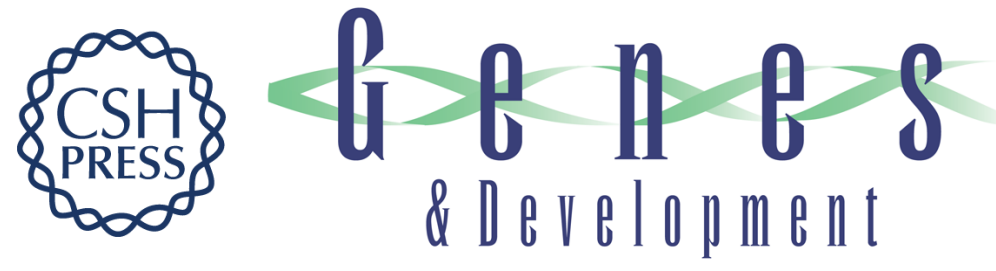

\section{Replication-coupled chromatin assembly is required for the repression of basal transcription in vivo.}

G Almouzni and A P Wolffe

Genes Dev. 1993, 7:

Access the most recent version at doi:10.1101/gad.7.10.2033

References This article cites 65 articles, 20 of which can be accessed free at:

http://genesdev.cshlp.org/content/7/10/2033.full.html\#ref-list-1

License

Email Alerting

Service

Receive free email alerts when new articles cite this article - sign up in the box at the top right corner of the article or click here.

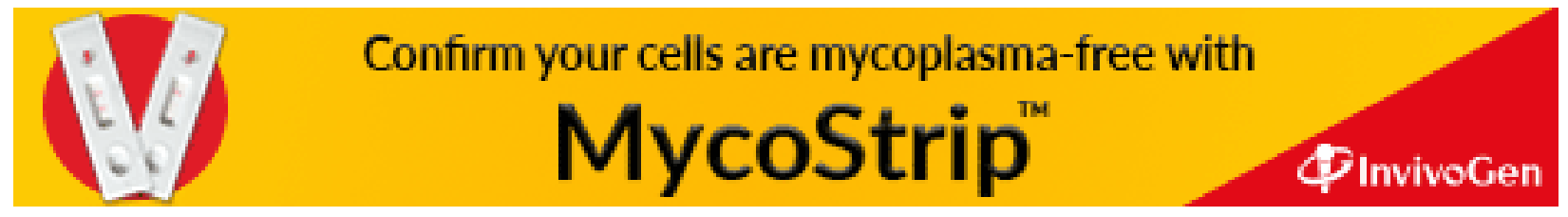

